\title{
Leah Macaden* \\ Being Dementia Smart (BDS): A Dementia Nurse Education Journey in Scotland
}

DOI 10.1515/ijnes-2015-0019

Received March 26, 2015; revised May 4, 2016; accepted May 4, 2016

\begin{abstract}
There is a global demographic transition secondary to population ageing. The number of older people living with multimorbidities including dementia has been significantly rising both in developed and developing countries. It is estimated that there would be 74.7 million people living with dementia by 2030 that would escalate to 135.46 million by $2050.62 \%$ of people with dementia currently live in low and middle income countries that are very poorly resourced to cope with this epidemic. Dementia is now duly recognised as a national priority within the UK and a global priority at the 2013 G8 Summit. Management and care of an individual with dementia requires a multidisciplinary approach with expertise and a competent skill base. Nurses are central to the delivery of dementia care delivery in hospitals, community and residential care settings. It is against this background that this pre-registration integrated dementia curriculum was developed to build capacity and capability with dementia expertise among the future nursing workforce in Scotland in line with the National Dementia Strategy.
\end{abstract}

Keywords: Dementia curriculum, pre-registration, nursing education, Scotland

The population demographics are changing globally with a dramatic age related demographic transition that poses significant implications for older people, policy makers, educators and service providers. It is projected that there would be more people over the age of 60 in comparison to 5 year olds by 2020 and by 2050, there would be two billion people worldwide over the age of 60 (World Health Organisation [WHO], 2015). The United Kingdom is no exception to this global phenomenon.
By 2035 in the United Kingdom (UK), the number of people aged 85 and over is projected to be almost 2.5 times larger than in 2010, reaching 3.5 million, accounting for 5 per cent of the total population. The population aged 65 and over will account for 23 per cent of the total population in 2035 (Office for National Statistics, 02 March 2012). Dementia that is increasingly becoming a common long term condition in older adults is a growing global challenge, with the number of people living with dementia set to rise sharply in the future; there are an estimated 74.7 million people with dementia worldwide by 2030 and this number is expected to grow to a 131.5 million by 2050 (Alzheimer's Disease International, August 2015). Recent estimates suggest that around 90,000 people in Scotland alone live with a diagnosis of dementia of which 3200 of them are below the age of 65 (Alzheimer Scotland, 2015). Dementia was declared as a public health priority in 2012 by the WHO (2012).

This scale of a dementia epidemic poses challenges to both public health and social care systems that imminently require resources, capability and capacity building alongside research to inform policy and practice through education (Muangpaisana, Intalapaprona, \& Assantachaia, 2008). Management and care of an individual with dementia requires a multidisciplinary/multiagency approach with expertise and a competent skill base. Nurses are well positioned and central to the delivery of dementia care both in the hospital and community setting.

Gaps in dementia specific knowledge and skills amongst staff working in hospital settings have been reported in previous research (Cowdell, 2010) with the lack of dementia training in acute care settings being described by staff as a significant unmet need (Galvin et al., 2010). Given this background, is there something missing in pre-registration nurse education which is perpetuating the same gap, even whilst preparing nurses for the future?

\section{Scotland's Dementia journey}

While rest of the UK has its own strategies and/or vision, Scotland has been very proactive and at the forefront in responding to this recently declared public health
*Corresponding author: Leah Macaden, School of Health Sciences, University of Stirling, Centre for Health Science Old Perth Road, Inverness IV2 3JH, United Kingdom, E-mail: leah.macaden@stir.ac.uk 
priority. The Scottish Government (SG) made dementia a national priority in 2007. This was followed by setting a national target on improving diagnosis rates in 2008 and publishing the first landmark National Dementia Strategy in 2010 (Scottish Government, June 2010). In line with this strategy, commitments were made by the SG to work in partnership with local government, voluntary, and private sectors to develop and implement national standards for dementia care. They also committed to workforce development through improving knowledge and skills among both health and social care professionals to enable better access to information and support for people diagnosed with dementia.

In addition to developing the dementia workforce in health and social care, the SG commissioned NHS Education for Scotland (NES) and the Scottish Social Services Council (SSSC) to produce a national framework for training that resulted in Promoting Excellence: A framework for all health and social services staff working with people with dementia, their families and carers (Scottish Social services Council and NHS Education for Scotland, 2011). This framework was launched alongside the Standards of Care for Dementia in Scotland in June 2011 (Scottish Government, 2011) and provides clear guidance for health and social care staff, focussing on the rights of the person with dementia and their family, carers, and supporters. The establishment of Alzheimer Scotland Dementia Nurse Consultants/ Specialists in the NHS Scotland Boards along with training Dementia Champions in health care, and Dementia Ambassadors in social care settings, have also been part of the wider initiative to support improvements in the care and support of people with dementia in Scotland.

Following a one-year consultation with various stakeholders and having achieved a higher rate of diagnosis than other parts of the UK, the second national strategy (Scottish Government, 2013) was published in 2013. This new strategy includes the education of health and social care professionals, and access to research teams with the capacity and expertise required to develop and evaluate innovative approaches to the care of people with dementia and their families.

\section{The Being Dementia Smart journey}

Nearly two thirds (65\%) of people admitted to hospital in the UK are over the age of 65 (Cornwell, Levenson, Sonola, \& Poteliakhoff, 2012). Nearly $50 \%$ of those admitted have some form of cognitive impairment that is inclusive of dementia and delirium (Royal College of Psychiatrists, 2005). Dementia training therefore is no longer only within the remit of training for mental health nurses, but needs to be within the core of all pre-registration nursing programmes. There are concerns internationally around deficiencies in knowledge, skills and attitudes among health professionals caring for people with dementia (Nolan, 2006; Fessey, 2007).

Within the UK, there is no mandatory dementia training in a large proportion of hospitals in England (Royal College of Psychiatrists, 2011). There are no prescribed guidelines for dementia specific training by professional regulators such as the Nursing and Midwifery Council (NMC, 2010) other than a generic requirement that nurses be prepared with specialised knowledge and skills to meet the needs of particular patient or vulnerable groups. This is open to interpretation and priorities within the curriculum by individual Higher Education Institutions (HEIs) depending on the resources and expertise available. Findings from the first national UK survey of higher education provision related to dementia care both within the pre-registration and Continuing Professional Development (CPD) programmes for health and social care professionals also confirm that the dementia curriculum content varied within the mental health branches of nursing and was dependent upon the experience and commitment of the lecturer to the subject. The survey also reported that specialised diploma and degree level courses on dementia towards CPD were not adequate (Pulsford, Hope, \& Thompson, 2007).

The author of this paper developed a post graduate module on Dementia within the School's strategic new Master's programme, a Master of Science in Health and Wellbeing of the Older Person, for health and social care professionals in early 2013. Formal and informal focus group interviews with undergraduate students identified significant gaps around content, continuity, and consistency in the dementia curriculum and resulted in mapping the dementia content within the pre-registration nursing programme (Adult \& Mental Health) at the School of Health Sciences, University of Stirling. However, the key driver behind the conceptualisation of this curriculum was the national policy to develop the workforce against the Promoting Excellence Knowledge \& Skills Framework in line with the 10-Point National Action Plan to support implementation of the Standards of Care for Dementia in acute care in Scotland as part of the second National Dementia strategy (Scottish Government, 2013). 


\section{A student's journey through Being Dementia Smart (BDS)}

The development of this Being Dementia Smart (BDS) curriculum was based the theory of constructivism that is closely related to cognitive theories and principles of adult learning where the educator assumes the role of a facilitator building cognitive bridges based on previous knowledge to develop more complex ideas as learning progresses (Brandon \& All, 2010). Based on this construct, the curriculum promotes incremental learning from Semester 1 through to Semester 8 and is based on the Promoting Excellence Framework (Figure 1) that incorporates the Stages of the Dementia Journey (Scottish Social services Council and NHS Education for Scotland, 2011).

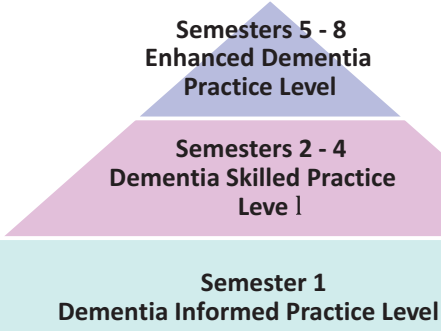

Figure 1: A student's journey through Being Dementia Smart.
The Promoting Excellence framework provides a clear indication of the knowledge, skills, and behaviours that are required by any individual who has infrequent (informed level of practice), substantial (skilled level of practice), and/ or regular and intense contact (enhanced level of practice) and as a provider of specialist care (expertise level of practice). Students make progress through this curriculum in an incremental manner through 8 semesters as outlined below.

\section{The BDS curriculum}

The curriculum underpins the standard that people with dementia have the right to have carers, which include nurses who are well supported and educated about dementia (Figure 2).

The curriculum content for Being Dementia Smart is student-centered and innovative, integrating technology and equipping students for the roles they will assume in practice (National League for Nursing, 2006). It is closely linked to health care needs such as dementia (Golden, 1982) in an ageing society, thus making it contextually relevant. The curriculum process also emphasizes the use of active learning strategies that will enhance both critical thinking and clinical reasoning amongst nursing students.

Content within the curriculum is mapped along the stages of the dementia journey and includes a comprehensive range of topics that include both the early and

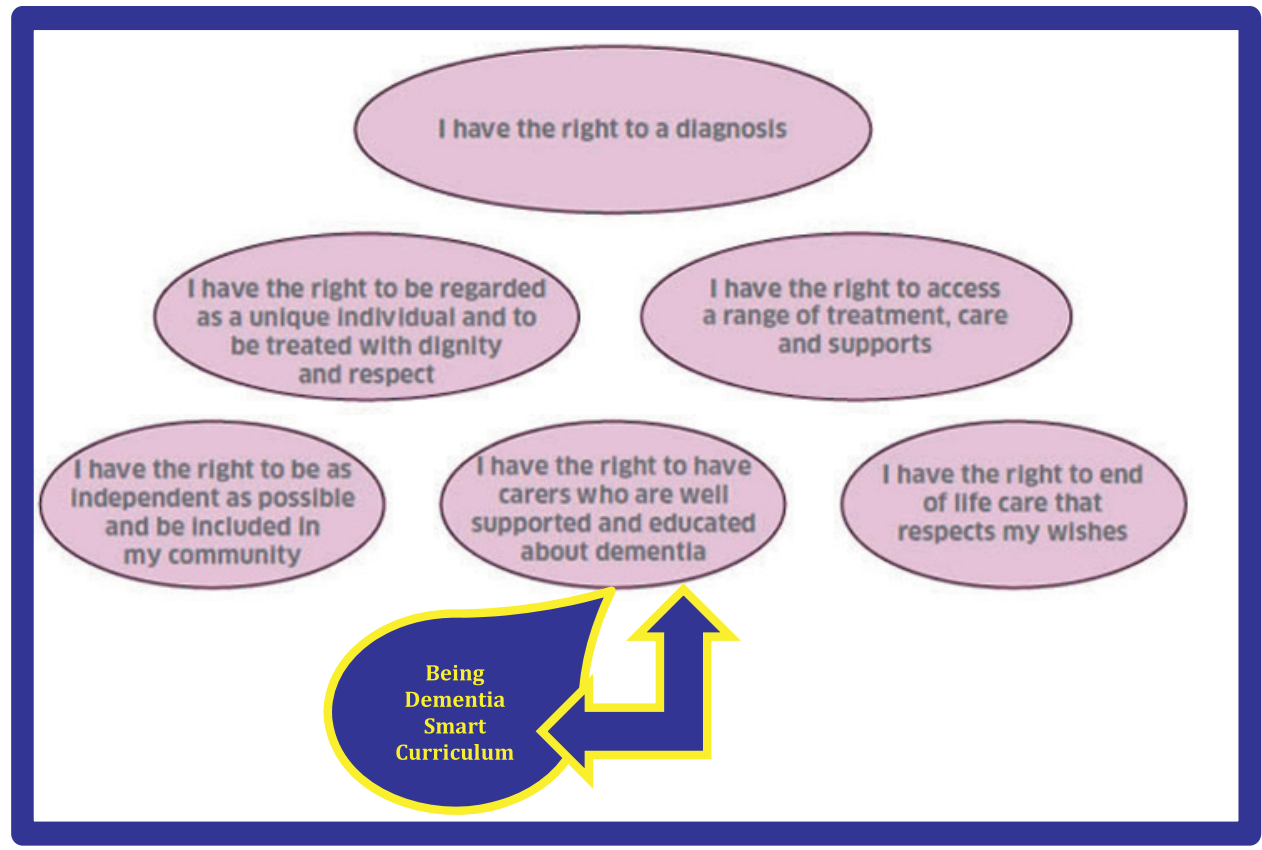

Figure 2: Standards of Dementia care in Scotland.

Source: Scottish Government (2011). 
advanced stages of dementia. Key aspects that are the core components of the curriculum and are relevant for dementia practice include: types of dementia, post diagnostic support, improving community connections, risk and vulnerability including risk enablement (Department of Health, 2010), assessment of cognition, function and behaviour, stress and distress, differentiating dementia, delirium and depression, impact of polypharmacy on cognition, end of life care including assessment and management of pain, carer support, and the role of environment and assistive technology.

Students have access to an extensive range of resources including a toolbox that is updated with current resources, semester specific learning outcomes, and assessments via the School's web platform. Students also have the unique opportunity of interactive learning with Dementia nurse consultants, Dementia Link Workers, Dementia Advisors and Dementia Service Managers in semesters 2, 4, and 5. The curriculum strengthens inter-disciplinary and multi-agency solutions to dementia care delivery through partnerships with Alzheimer Scotland, a leading dementia organization in Scotland that works closely with the Scottish Government on policy initiatives. This partnership creates opportunities for students to engage with the local dementia resource centres in addition to empowering students to take an active role in driving improvements in care and enabling them to develop personal, academic, and clinical expertise in dementia from both a hospital and community perspective. Development of this curriculum has provided excellent opportunities for mutual sharing of dementia expertise and resources enabling exchange of organisational culture and values to enhance the quality of education.

The learning outcomes focus on students being able to:

1. Gain an improved understanding and expertise in the specialist knowledge and skills required to support and deliver care for someone with dementia at an enhanced level within the Promoting Excellence Framework.

2. Develop original and creative responses to challenging/complex situations and make informed decisions/judgments in hospital and community settings.

3. Demonstrate improved levels of confidence and competence with reflective practice skills in providing person-centered care, including carer support, for people living with dementia.

Teaching and learning methods (Figure 3) include a combination of lectures, skills workshops, small group discussions, interactive web based resources, self-learning, and reflection. Some of the innovative features within BDS include experiential learning through simulation in Semester 1 prior to the students' first practice placement in order to raise awareness on the impact of sensory and cognitive impairment in older adults particularly with dementia. Six learning stations called 'micro worlds' were created 'for students to experience visual, hearing, and dual sensory impairments followed by reflection and debrief (Wilford \& Doyle, 2006) (Bruce, Bridges, \& Holcomb, 2003). Workshop evaluation was carried out using reflections at each station and an online questionnaire. Small group discussions in semester 3 enable students to use

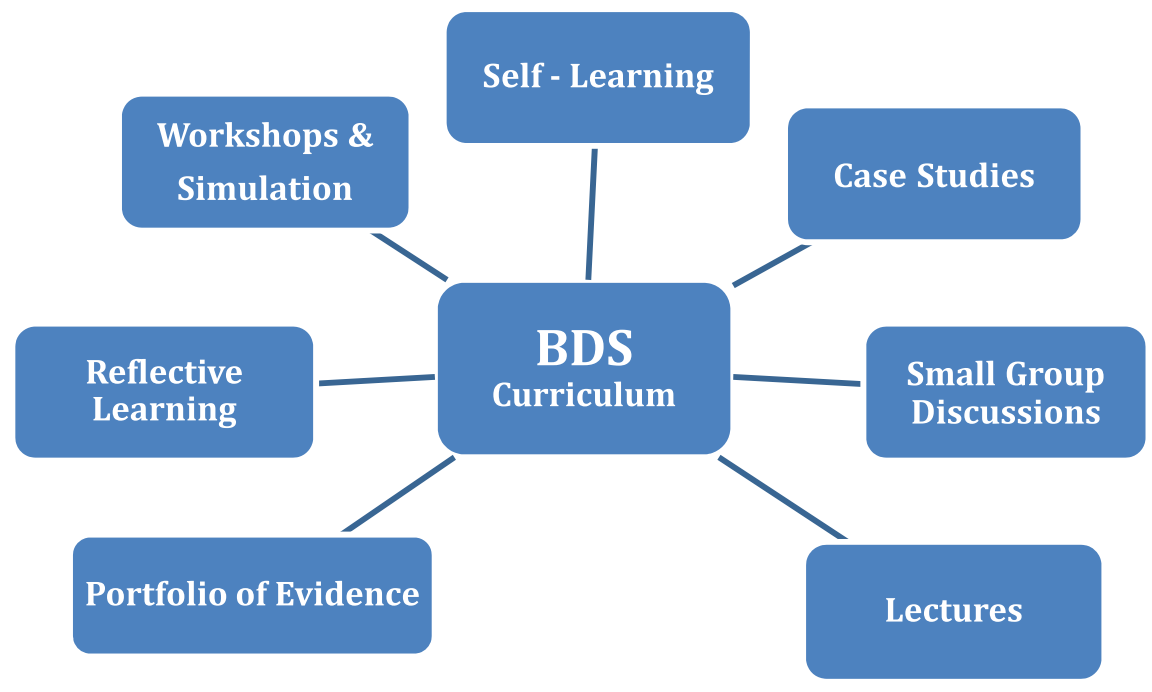

Figure 3: Teaching \& learning methods. 
a traffic light tool to categorise risks using case studies and understand the concept of risk enablement (Department of Health, 2010; Morgan, 2004) in people with dementia. Seminar groups in semester 8 facilitate learning about the role of environment and assistive technology in supporting people living with dementia using virtual care home and hospital settings followed by debrief and feedback.

Students are expected to engage with all the essential learning resources each semester and provide evidence of engagement towards a BDS portfolio (Figure 4). This includes attendance and participation at lectures, seminars, small group discussions, workshops, submission of reflective reports, and completion of quizzes with grades set to be achieved. The portfolio is an effective tool that facilitates reflective learning, developing skills of autonomy and decision making with increased control over the learning process to support studentcentered learning (Jasper, 1995). Students undergo formative assessments that include quizzes, reflections, case based scenarios in conjunction with building evidence for their portfolio. This portfolio is required to be signed off by the personal tutors along with the Ongoing Achievement Record (OAR) that records the induction, interim assessment of progress, and final assessment of performance each semester for the practice component in the pre-registration graduate nursing programme in Scotland.
The BDS portfolio linked to OAR has facilitated two distinct advantages. First, all academic staff in the school are now familiar with the BDS curriculum with having to sign off the evidence towards the BDS portfolio. This has raised the profile of Dementia within the school. Second, all academic staff in the school are also able to contribute towards the workforce development in their personal tutor role with the BDS portfolio, in line with the National Dementia Strategy in Scotland. irrespective of their professional expertise.

The distinct features of this educational initiative are that it is strategic within the current global health priorities (Golden, 1982), underpinned by policy, delivered using a multiagency approach through collaborative and shared learning (Clifton, Dale, \& Bradshaw, 2006) and is linked to the Promoting Excellence Framework. As an integrated curriculum across both adult and mental health branches of nursing, BDS has enabled students from both these branches to interact and share perspectives around the complexities of caring for people with dementia both from a physical and mental health perspective that is mutually beneficial across the two branches of nursing. Since 2014, BDS has provided an enviable opportunity to approximately 300 students from each cohort exiting the graduate nursing programme within the Promoting Excellence Framework. The preregistration nursing programme is currently delivered across three campuses in partnership with three NHS

Registration Number:

\begin{tabular}{|l|l|l|l|l|}
\hline \multicolumn{1}{|c|}{ Semester } & Signature of Student & Date & \multicolumn{1}{c|}{$\begin{array}{c}\text { Signature of Personal } \\
\text { Tutor }\end{array}$} & Date \\
\hline Semester 1 & & & & \\
\hline $\begin{array}{l}\text { Lead Lecture 1 - Introduction to } \\
\text { Ageing }\end{array}$ & & & & \\
\hline $\begin{array}{l}\text { Lead Lecture 2 - Pathophysiology. } \\
\text { Types. Symptoms and an } \\
\text { overview on Dementia }\end{array}$ & & & & \\
\hline $\begin{array}{l}\text { Sensory and Cognitive Impairment } \\
\text { in older adults - Simulation } \\
\text { Workshop }\end{array}$ & & & & \\
\hline $\begin{array}{l}\text { Completion of Dementia Quiz 1 } \\
\text { Semester 2 }\end{array}$ & & & & \\
\hline $\begin{array}{l}\text { Lead Lecture 3 - The role of } \\
\text { Alzheimer Scotland in dementia } \\
\text { care }\end{array}$ & & & & \\
\hline $\begin{array}{l}\text { Dangling Conversations - A } \\
\text { Reflective account }\end{array}$ & & & & \\
\hline Semester 3 & & & & \\
\hline $\begin{array}{l}\text { Small Group Discussion - Risk \& } \\
\text { Vulnerability }\end{array}$ & & & & \\
\hline $\begin{array}{l}\text { The Traffic Light Tool - Risk } \\
\text { assessment }\end{array}$ & & & & \\
\hline Semester 4 & & & & \\
\hline $\begin{array}{l}\text { Lead Lecture 4 Assessment of } \\
\text { Cognition. Function and Behaviour } \\
\text { in Dementia }\end{array}$ & & & & \\
\hline $\begin{array}{l}\text { Think Capacity, Think Consent - } \\
\text { Scenario Based Questions }\end{array}$ & & & & \\
\hline
\end{tabular}

Figure 4: BDS portfolio. 
Boards in Scotland (Forth Valley, Highland and the Western Isles). Therefore, it was crucial to ensure that the dementia curriculum be consistent across the three campuses in order to build the future workforce for Scotland in line with the national strategy. Consistency with training and support has also been ensured on all three campuses through BDS Campus Coordinators.

\section{BDS beyond Scotland}

Working with older people has not been an attractive career option within nursing worldwide. Subject expertise, a competent skill base, positive attitudes, awareness of local and national policies, quality of curricula and professional passion contribute towards developing clinical leadership (Aberdeen \& Angus, 2005) which is something that needs to be developed for dementia care. A programme such as this could not be more relevant and timely beyond the local context in Scotland. Data projection for global prevalence on dementia is alarming, with $68 \%$ of people with dementia living in low and middle income countries by 2050 (Alzheimer's Disease International, August 2015). The G8 Summit (Alzheimer's Society, 2013) has drawn attention to the global impact of dementia suggesting that governments in all countries ensure strategic policies in place to manage the increasing number of people who have dementia. and their families. Eleven countries around the world the UK (England, Scotland, Wales and Northern Ireland), Australia, Denmark, Finland, France, South Korea, USA, Norway, the Netherlands, Luxembourg and Belgium have responded thus far developing and implementing National Dementia Plans. A review of seven of these national plans fittingly recommends improving training for health care professionals with the formulation of core competencies with continuous education and training across a range of settings including hospitals as one of the ten core recommendations. (Pot \& Petrea, 2013).

A study on higher education provision for professionals working with dementia (Pulsford et al., 2007) concluded that further research was required around the fitness for purpose of dementia education for health and social care professionals. The G8 Dementia Summit recognises the need for global research as the strategy for an effective international response to dementia (Alzheimer's Society, 2013). Effective education and training strategies for health and social care professionals in tandem with research strategies will prove to be an even better global response. Investing in education and training of all frontline staff needs be at the core of national dementia policies and standards of dementia care in the future.

\section{Conclusion}

BDS is a proactive response to the National Action Plan for Dementia in Scotland to develop the future nursing workforce against the Promoting Excellence Knowledge \& Skills Framework. Stipulation of dementia training within the training for health care professionals is probably the way forward towards building capacity and capability in the future health workforce given the global magnitude of dementia prevalence. This new integrated dementia curriculum within the pre-registration graduate nursing programme has been embraced with enthusiasm both by staff and students in the school since its launch in September 2014. There has been a significant expression of interest from students to complete the requirements and exit the programme with enhanced level of dementia training. It is therefore interesting to note this shift in paradigm with nursing students at such an early stage of their career. Funding opportunities are being pursued towards a formal evaluation of this curriculum through research and global dissemination of this model of dementia curriculum in the pre-registration programmes for medical, nursing and allied health disciplines within health care.

Acknowledgements: The author would like to acknowledge input and support from Sandra Bannister, former Director of Undergraduate Programme at the School of Health Sciences, University of Stirling, towards the implementation of this curriculum within the pre-registration graduate nursing programme. She would also like to acknowledge the support received from Ruth Mantle, Alzheimer Scotland Dementia Nurse Consultant, NHS Highland in developing this curriculum. The author would specially like to acknowledge the commitment and support of all her colleagues within the school for facilitating this programme. 


\section{References}

Aberdeen, S., \& Angus, J. (2005). A systematic approach to curricula development for aged-care leadership. Educational Gerontology, 31(6), 481-497.

Alzheimer Scotland. (2015). Number of people with dementia in Scotland 2015. Retrieved from http://www.alzscot.org/cam paigning/statistics

Alzheimer's Disease International. (August 2015). The global impact of dementia - an analysis of prevalence, incidence, cost and trends. London: Alzheimer's Disease International.

Alzheimer's Society. (2013). G8 summit on dementia. Retrieved from http://www.alzheimers.org.uk/G8summit

Brandon, A. F., \& All, A. C. (2010). Constructivism theory analysis and application to curricula. Nursing Education Perspectives, 31(2), 89-92. doi:10.1043/1536-5026-31.2.89.

Bruce, S., Bridges, E. J., \& Holcomb, J. B. (2003). Preparing to respond: Joint trauma training center and USAF nursing war skills simulation laboratory. Critical Care Nursing Clinics of North America, 15(2), 149-162.

Clifton, M., Dale, C., \& Bradshaw, C. (2006). The impact and effectiveness of interprofessional education in primary care: An RCN literature review. London: Royal College of Nursing.

Cornwell, J., Sonola, L., Levenson, R., \& Poteliakhoff, E. (2012). Continuity of care for older hospital patients: $A$ call for action. London: King's Fund.

Cowdell, F. (2010). International Journal of Older People's Nursing, 5(2), 83.

Department of Health. (2010). Nothing ventured, nothing gained. London: Department of Health.

Fessey, V. (2007). Patients who present with dementia: Exploring the knowledge of hospital nurses. Nursing Older People, 19(10), 29-33.

Galvin, J. E., Kuntemeier, B., Al-Hammadi, N., Germino, J., MurphyWhite, M., \& McGillick, J. (2010). Dementia-friendly hospitals: care not crisis: an educational program designed to improve the care of the hospitalized patient with dementia. Alzheimer Disease and Associated Disorders, 24(4), 372.

Golden, A. S. (1982). A model for curriculum development linking curriculum with health needs. In A. S. Golden, D. G. Carlson \& J. L. Hogan (Eds.), The art of teaching primary care (pp. 9-25). New York: Springer Publishing Co.

Jasper, M. (1995). The portfolio workbook as a strategy for studentcentred learning. Nurse Education Today, 15(6), 446-451 6p.

Morgan, S. (2004). Positive risk taking: An idea whose time has come. Health Care Risk Report, 10(10), 18-19.

Muangpaisana, W., Intalapaprona, S., \& Assantachaia, P. (2008). Attitudes of medical students and residents towards care of the elderly. Educational Gerontology, 34(5), 400.
National League for Nursing. (2006). Excellence in nursing education model. New York: National League for Nursing.

Nolan, L. (2006). Caring connections with older persons with dementia in an acute hospital setting - a hermeneutic interpretation of the staff nurse's experience. International Journal of Older People Nursing, 1, 208-215.

Nursing and Midwifery Council. (2010). Standards for pre - registration nursing education. Retrieved from http://standards. nmcuk.org/PreRegNursing/statutory/Standards/Pages/ Standards.aspx

Office for National Statistics. (02 March, 2012). Population ageing in the united kingdom, its constituent countries and the European union Retrieved from http://www.ons.gov.uk/ons/dcp171776_ 258607.pdf

Pot, A. M., \& Petrea, I. (2013). Bupa/ADI report: 'Improving dementia care worldwide: Ideas and advice on developing and implementing a national dementia plan'. London: Bupa/ADI.

Pulsford, D., Hope, K., \& Thompson, R. (2007). Higher education provision for professionals working with people with dementia: A scoping exercise. Nurse Education Today, 27(1), 5-13. doi:http://dx.doi.org/10.1016/j.nedt.2006.02.003.

Royal College of Psychiatrists. (2005). Improving the outcome for older people admitted to the general hospital: Guidelines for the development of liaison mental health services for older people. London: Royal College of Psychiatrists.

Royal College of Psychiatrists. (2011). Report of the national audit of dementia care in general hospitals. London: Royal College of Psychiatrists.

Scottish Government. (June 2010). Scotland's national dementia strategy. Retrieved from http://www.scotland.gov.uk/ Resource/Doc/324377/0104420.pdf

Scottish Government. (2011). Standards for care for dementia in Scotland. Retrieved from http://www.scotland.gov.uk/ Resource/Doc/350188/0117212.pdf

Scottish Government., (2013). Scotland's national dementia strategy 2013-2016. Retrieved from http://www.scotland.gov.uk/ Topics/Health/Services/Mental-Health/Dementia

Scottish Social services Council and NHS Education for Scotland. (2011). Promoting excellence: A framework for all health and social services staff working with people with dementia, their families and carers. Retrieved from http://www.scotland.gov. uk/Resource/Doc/350174/0117211.pdf

Wilford, A., \& Doyle, T. J. (2006). Product focus. Integrating simulation training into the nursing curriculum. British Journal of Nursing, 15(17), 926.

World Health Organisation. (2012). Dementia: Retrieved from: A public health priority. Retrieved from http://www.who.int/ mental_health/publications/dementia_report_2012/en/

World Health Organisation. (2015). World report on ageing and health. Luxembourg: World Health Organisation. 


\section{Being Dementia Smart Portfolio of Evidence - Appendix 1}

Student Name:

Registration Number:

Semester

\section{Semester 1}

Lead Lecture 1 - Introduction to Ageing

Lead Lecture 2 - Pathophysiology, Types, Symptoms and an overview on Dementia

Attendance at Sensory Workshop

Completion of Dementia Quiz 1

Semester 2

Lead Lecture 3 - The role of Alzheimer Scotland in

dementia care

Dangling Conversations - A Reflective account

\section{Semester 3}

Small Group Discussion - Risk \& Vulnerability

The Traffic Light Tool - Risk assessment

\section{Semester 4}

Lead Lecture 4 - Assessment of Cognition, Function and Behaviour in Dementia

Think Capacity, Think Consent - Scenario Based Questions

\section{Semester 5}

Lead Lecture 5 - Differentiating the Three Ds Dementia, Delirium \& Depression

Lead Lecture 6 - Stress and Distress in Dementia

Completion of Dementia Quiz 2

Semester 6

Lead Lecture 7 - Polypharmacy and its impact on cognition Skills Workshop

\section{Semester 7}

Lead Lecture 8 - Pain assessment in Dementia

Lead lecture 9 - End of life care in dementia Completion of Dementia Quiz 3

Semester 8

Attendance at Group Work on Dementia-Friendly Design and Environment

Signature of Student

Date

Signature of Personal Tutor

Date 


\section{Semester Specific Learning Outcomes Sample (Appendix 2)}

\begin{tabular}{|c|c|c|c|}
\hline Semester & $\begin{array}{l}\text { Level within the Promoting Excellence } \\
\text { Framework }\end{array}$ & Learning Outcomes (Knowledge) & Learning Outcomes (Skill/Ability) \\
\hline Semester 4 & $\begin{array}{l}\text { Skilled Practice Level } \\
\text { The Dementia Skilled Practice Level } \\
\text { outlines the knowledge and skills } \\
\text { required by all health and social services } \\
\text { workers who have direct and/or } \\
\text { substantial contact with people who have } \\
\text { dementia. }\end{array}$ & $\begin{array}{l}\text { Students will be able to: } \\
\checkmark \text { Gain confidence in performing and } \\
\text { interpreting evidence-based } \\
\text { assessments related to cognition, } \\
\text { function (ADLs) and behaviour as } \\
\text { required in people with dementia; } \\
\checkmark \text { Understand the human and legal } \\
\text { rights of people with dementia for } \\
\text { decision making/choices in the } \\
\text { context of their own lives. }\end{array}$ & $\begin{array}{l}\text { Students will be able to: } \\
\checkmark \text { Participate, contribute and interpret } \\
\text { evidence-based MDT assessments in } \\
\text { practice settings; } \\
\checkmark \text { Actively support people with } \\
\text { dementia, their families and carers, to } \\
\text { understand the legal frameworks that } \\
\text { facilitate choice and decision making. }\end{array}$ \\
\hline Semester 5 & $\begin{array}{l}\text { Enhanced Dementia Practice } \\
\text { The Enhanced Dementia Practice Level } \\
\text { outlines the knowledge and skills } \\
\text { required by health and social care } \\
\text { workers who have more regular and } \\
\text { intense contact with people with } \\
\text { dementia, provide specific interventions, } \\
\text { and/or direct and manage care and } \\
\text { services for people with dementia. }\end{array}$ & $\begin{array}{l}\text { Students will be able to: } \\
\checkmark \text { Understand the causes and signs } \\
\text { of stress and distress for the } \\
\text { person with dementia, their family } \\
\text { and carers (formal \& informal); } \\
\checkmark \text { Differentiate between signs of } \\
\text { delirium, depression and } \\
\text { depression in a practice setting; } \\
\checkmark \text { Appreciate the concept of } \\
\text { relationship-centred model of care } \\
\text { in dementia practice settings. }\end{array}$ & $\begin{array}{l}\text { Students will be able to: } \\
\checkmark \text { Recognise triggers of Stress and } \\
\text { Distress and intervene as appropriate; } \\
\checkmark \text { Recognise when a person with } \\
\text { dementia, their families and carers, } \\
\text { are experiencing anxiety and/or } \\
\text { depression and seek appropriate } \\
\text { resources to support them. }\end{array}$ \\
\hline
\end{tabular}

